\title{
Impasses e reflexões sobre o papel do conselho tutelar
}

Impasses and reflections on the role of the tutelary council

\section{Debora Ruite de Paiva Mota}

Graduada em Serviço Social pela Universidade do Estado do Rio Grande do Norte - UERN.

\section{Ana Luiza Pereira Holanda}

Graduanda de Serviço Social pela Universidade Potiguar - UnP.

\section{Maciana de Freitas e Souza}

Especialização em Saúde Pública com Ênfase em Saúde da Família pela Faculdade do Vale do Jaguaribe - FVJ.

\section{Resumo}

Este trabalho tem por objetivo analisar o papel do conselho tutelar, bem como seus desafios para a garantia de direitos do segmento infantojuvenil. A metodologia utilizada foi uma pesquisa bibliográfica. Com base na literatura, iniciativas que visam o aperfeiçoamento dos conselheiros e do trabalho em rede são fundamentais para que seja efetivada a proteção integral.

Palavras-chave: Criança e adolescente; Conselho Tutelar; Violência intrafamiliar.

\section{Abstract}

This work aims to analyze the role of the tutelary council, as well as its challenges for guaranteeing the rights of children and adolescents. The methodology used for a bibliographic search. Based on the literature, initiatives aimed at the improvement of counselors and networking are fundamental for the full protection to take place.

Keywords: Child and adolescent; Guardianship Council; Intra-family violence. 


\section{Materialização da política de proteção integral no Brasil}

O Brasil tem como marco os 30 anos do Estatuto da Criança e do Adolescente e da Doutrina da Proteção Integral. Vinculado à construção de um projeto de transformação social, os seus artigos $3^{\circ}$ e $4^{\circ}$ (Brasil, 1990) determinam que é dever da família, do Estado e da sociedade em geral garantir o acesso aos direitos fundamentais. $\mathrm{Na}$ linha de entendimento construída, com a abolição do Código de Menores, o Estatuto estabelece que os adolescentes são sujeitos de direitos e que devem ser tratados com prioridade absoluta.

A descentralização administrativa da política de proteção integral é um mecanismo diferencial inovador que traz a sociedade para participar ativamente das decisões e deliberações das políticas sociais. O Estatuto da Criança e do Adolescente institui os direitos do segmento infantojuvenil, bem como evidencia a participação das instituições na responsabilização pela efetivação dos direitos. Segundo Amin, esta lei se baseia em três princípios orientadores do direito da criança e do adolescente que são: “a) princípio da prioridade absoluta; b) princípio do melhor interesse; c) princípio da municipalização" (2010, p.19).

Em seu Art. 86, que trata da política de atendimento, vê-se a importância da união de todas as esferas do poder público para efetivar os direitos das crianças e dos adolescentes. “A política de atendimento dos direitos da criança e do adolescente far-se-á através de um conjunto articulado de ações governamentais e não governamentais, da União, dos Estados, do Distrito Federal e dos Municípios.” (Brasil, 2011), a pactuação entre os três poderes favorece a descentralização das ações assistenciais, em seus aspectos gerenciais, conforme abordagem abaixo:

Por descentralização político-administrativo compreende-se a distribuição do poder por todas as entidades federativas, que, de forma harmônica e complementar, responsabilizam-se pela definição e pela execução da política de atendimento. A participação popular, neste caso, consiste no chamamento da sociedade a colaborar no processo no processo de formulação das políticas públicas, bem como a controlar as ações governamentais em todos os níveis. (Tavares, 2010, p. 303)

Diante do exposto, a municipalização é um fator fundamental para a política de atendimento, pois a descentralização administrativa permite que o poder público local faça a implementação, a fiscalização e a adaptação dos programas de abrangência social à realidade local. Segundo Amin (2010, p. 29), a descentralização administrativa é muito importante, pois 
MOTA, Debora Rute de Paiva; SOUZA, Maciana de Freitas e; HOLANDA, Ana Luiza Pereira. Impasses e reflexões sobre o papel do conselho tutelar. Dignidade Re-Vista, v.6, n.11, dez 2020.

é a partir dela que foi reservada "a execução dos programas de política assistencial à esfera estadual e municipal, bem como entidades beneficentes e assistência social."

A descentralização e a ampliação da assistência social previstas nos Arts. 203 e 204 da $\mathrm{CF} / 88$ atribuíram à União a competência de elaborar as normas gerais e coordenação de programas assistenciais. Logo, é fundamental a união destes para que se efetive a Doutrina de Proteção Integral como preconizado no Estatuto.

O Art.86 do ECA menciona que a política de atendimento dos direitos da criança e do adolescente será realizada por um conjunto articulado de ações governamentais e não governamentais, da União, dos Estados, do Distrito Federal e dos Municípios. Esse artigo do Estatuto confirma o já exposto no Art. 227 da CF/88, que tanto o Estado quanto a família e a sociedade têm responsabilidade no que diz respeito às questões infantojuvenis.

Nas linhas de ação da política de atendimento estabelecida pelo ECA, é importante ressaltar aqui o inciso II do Art.87 da lei estatutária que exige "políticas e programas de assistência social, em caráter supletivo para quem deles necessitem”. Observa-se então a nova concepção da Assistência Social no Brasil, entendendo-a como política pública, compondo ações em duas categorias de atenção a sociedade: a básica e a especial.

Os serviços básicos previnem situações de riscos por meio do fortalecimento de vínculos familiares e comunitários, com vistas a desenvolver as potencialidades individuais dos sujeitos envolvidos. Já os serviços de atenção especial são destinados às pessoas que se encontram em situação de risco ou de violação de direitos.

É atribuída ao Conselho Nacional dos Direitos da Criança e do Adolescente (Conanda) a responsabilidade de formular as políticas e as normas gerais para que cada município disponha de uma rede de atendimento que atue de forma articulada no combate à violação dos direitos fundamentais da criança e do adolescente, conforme o artigo 91:

(...) as entidades não governamentais somente poderão funcionar depois de registradas no Conselho Municipal dos Direitos da Criança e do Adolescente, o qual comunicará o registro ao Conselho Tutelar e à autoridade judiciária da respectiva localidade.

$\S 1^{\circ}$ Será negado o registro à entidade que

a) não ofereça instalações físicas em condições adequadas de habitabilidade, higiene, salubridade e segurança;

b) não apresente plano de trabalho compatível com os princípios desta Lei;

c) esteja irregularmente constituída;

d) tenha em seus quadros pessoas inidôneas.

e) não se adequar ou deixar de cumprir as resoluções e deliberações relativas à modalidade de atendimento prestado expedidas pelos Conselhos de Direitos da Criança e do Adolescente, em todos os níveis (Brasil, 2011, p.48) 
Um avanço significativo após a promulgação do ECA foi a criação dos Conselhos Municipais de Direitos (Condica) e Conselhos Tutelares (CT), estes presentes na maioria dos municípios brasileiros. A criação do CT e do Condica é de cunho obrigatório, pois o Estatuto da Criança e do Adolescente determina que cada município deverá criar e fazer funcionar os seus Conselhos, o de Direitos, os Tutelares e também o Fundo Municipal. Esses órgãos têm a função de cuidar para que os direitos das crianças e adolescentes sejam cumpridos (Tavares, 2010).

Dessa forma, a municipalização da política de atendimento, permite compreender que a responsabilidade com a infância e a adolescência não está somente com a família. Ela vai além, ultrapassa a esfera familiar, recai sobre a comunidade e também sobre o poder público, sendo este último, segundo o ECA em seu art.88, inciso I, o principal executor da política de atendimento destinado ao grupo infantojuvenil.

A criação dos Conselhos Tutelares se dará por meio de Lei Municipal, que deverá também disciplinar o processo de escolha dos conselheiros tutelares pela comunidade local. De acordo com o artigo 132 do Estatuto da Criança e do Adolescente, consta que "em cada município haverá, no mínimo, um Conselho Tutelar composto de cinco membros, escolhidos pela comunidade local para mandato de três anos, permitida uma recondução.” (Brasil, 2011, p.62)

Desse modo, a municipalização da política de atendimento à criança e ao adolescente significa uma estratégia de enfrentamento que fortalece o poder local no município para combater as diversas violações dos direitos das crianças e dos adolescentes. Segundo Campos (2009), o controle social é um conjunto de ações desenvolvidas que tem como objetivo o monitoramento, a físcalização e a avaliação sobre determinada política constituída e desenvolvimento no âmbito de sua jurisdição, envolvendo a participação da sociedade civil na definição de políticas e fiscalização de ações governamentais.

Segundo Santos et al (2019), o Brasil possui cerca de 5.472 Conselhos Tutelares, com cobertura de 98,3\% dos municípios. O Conselho Tutelar é um espaço permanente e autônomo, não jurisdicional, responsável por zelar pelo cumprimento dos direitos da criança e do adolescente. Já os conselhos de direitos são instituições voltadas à participação social, que têm como objetivo a materialização de políticas públicas de acordo com a proposta constitucional. Segundo Faleiros, "o controle social dos conselhos sobre as políticas municipais pode ser mais ou menos exercido segundo as correlações de forças dentro dos próprios conselhos" (2009, p.83). 
O controle social se constitui como um dos instrumentos de fiscalização que visa o cumprimento das ações e o acompanhamento da execução de políticas públicas formuladas pelo Estado. É importante salientar que a criação dos conselhos se configura como um dos canais de possibilidades de participação social, inscritos em vários campos das políticas sociais. Todavia, nem todo conselho se configura apenas canal de participação, alguns apresentam características específicas, como é o caso dos CT que desenvolvem papel fundante e interventivo no combate à violência contra criança e adolescente.

\title{
Atribuições e competências do conselho tutelar
}

Segundo Faleiros (2009), uma vez que o Conselho Tutelar se trata de um órgão encarregado de cuidar para que os direitos das crianças e dos adolescentes brasileiros não sejam violados, mas preservados e garantidos, suas atribuições encontram-se voltadas para uma intervenção direta que proporcione mudanças significativas. Nesse sentido, as ações realizadas pelos conselheiros tutelares devem se respaldar em um princípio ético-político frente às violações de direitos, devendo estar diretamente ligadas a uma doutrina de proteção integral dos jovens e adolescentes.

Tais práticas devem ser realizadas com compromisso integral com vistas à garantia de direitos e responsabilidade de acordo como a função que lhe compete. No entanto, conforme Santos et al. (2019) muitos são os desafios, na realidade concreta, da rede de atendimento:

\begin{abstract}
A literatura indica, como problemas presentes na rede de enfrentamento da violência infantil, a morosidade do sistema de defesa e de responsabilização (segurança pública, Ministério Público e Justiça), a insuficiência de políticas socioassistenciais e educacionais, a escassez e, mesmo, a inexistência de vários serviços e ações fundamentais, em especial, os de saúde mental, além do reduzido número de profissionais que atuam nas organizações e nos serviços. (2019, p.144)
\end{abstract}

As atribuições do Conselho Tutelar encontram-se dispostas no artigo 136, do ECA, que se apresentam sob uma sucinta discussão apresentada. No inciso I, o CT deve atender todas “as crianças e adolescentes nas hipóteses de ameaça ou violação dos direitos, seja por ação ou omissão da sociedade ou do Estado; por falta, omissão ou abuso dos pais ou responsável; em razão da sua conduta" previstos no Art. 98 desta lei. Quando se verifica um ato infracional cometido por uma criança, o Art. 105 prevê que: "Ao ato infracional praticado por criança corresponderão as medidas previstas no Art. 101” (Brasil, 1990). Assim, o Conselho Tutelar deve procurar os pais ou os responsáveis e, mediante o termo de responsabilidade, deve 
prestar orientação e dar apoio temporário a essa família, dentre outras medidas explicitadas nos incisos que compõem o Art. 101.

Os artigos acima citados definem de forma precisa a missão de proteção do Conselho Tutelar. A sua ação não pode se limitar à cultura, à classe social ou ao território da criança/adolescente, já que todas elas são possuidores de direitos que, quando colocados sob o ponto de vista da ameaça ou de sua violação, devem ser rapidamente resgatados. Isto posto, cabe ao Conselho Tutelar, enquanto órgão responsável, adotar providências contra a violação de direitos, sejam estas violações praticadas por parte do Estado, da sociedade ou da própria família. A sua atuação não pode se limitar à distinção de nenhum desses agentes.

Podemos perceber que a responsabilidade do Estado está para além da proteção de crianças e de adolescentes, pois ela se estende no sentido de propiciar mecanismos para que toda a família consiga sair das possíveis situações de vulnerabilidade e risco. Deve ser função do Estado manter programas e serviços que respondam à realidade e necessidade de cada uma delas, que devem ser de conhecimento do conselho e demais integrantes da sociedade para que os encaminhamentos sejam realizados de forma correta, impactando, minimizando ou erradicando a situação de violência em questão. Como indica Santos et al. (2019):

\begin{abstract}
Destaca-se que, para o enfrentamento da violência infantil, é preciso superar as fragilidades da rede e promover ações integradas e efetivas entre os diversos serviços e atores sociais.Para superar estas condições, exigem-se movimento intenso e contínuo, articulação de vontades, diálogo permanente entre os atores, busca de parceiros e capacitação permanente para o trabalho coletivo e intersetorial. (2019, p.145)
\end{abstract}

Nesse contexto, é importante ressaltar que a falta de integração dos serviços e capacitação adequada às equipes de atendimento pode contribuir para que as crianças passem por mais uma violação de direito, portanto é necessário enxergar que uma relação profissional que pretende mudanças substantivas, além da dimensão técnica, também necessita ser uma relação humanizada.

Desse modo, para que possam exercer um controle social real e efetivo, faz-se necessário garantir a transparência das políticas desenvolvidas, de modo que os conselheiros possam ter acesso às informações para que sejam capazes de contextualizar e refletir sobre a política de atendimento juvenil e assim promover um controle social efetivo no âmbito do conselho com vistas a avaliar e reforçar a centralidade dos direitos.

Discutir a relevância do Conselho Tutelar é, antes de tudo, um exercício de reflexão sobre a sociedade e suas mudanças. Mudanças que abrangem noções conceituais, tais como as 
que influenciaram a Constituição Federal de 1988 e o Estatuto da Criança e do Adolescente, que veio confirmar as reivindicações dos movimentos populares por melhorias e garantias dos direitos sociais para esse segmento. Como indica Santos et al. (2019) "é válido salientar, ainda, que a violência é uma questão da práxis sociopolítica, e sua superação requer conhecimento das condições que a engendram" (2019, p.143).

\section{Considerações finais}

É evidente a importância de que os poderes públicos - seja das esferas municipais, estaduais ou federais - olhem com mais atenção para esse âmbito, com o objetivo de fortalecer e potencializar ainda mais o trabalho do conselho tutelar. Do contrário, cabem aos conselheiros a mobilização e a reivindicação com o apoio da população por melhores condições de trabalho. Como o ECA assegura, é dever da família, da sociedade e do Estado o cumprimento dos direitos da criança e do adolescente, e esses têm a absoluta prioridade na formulação de políticas públicas e destinação privilegiada de recursos nas dotações orçamentárias das diversas instâncias político-administrativas do país.

A ideia deste artigo foi refletir sobre o papel do Conselho Tutelar a partir de uma perspectiva crítica, e consideramos que a elaboração de uma análise mais aprofundada acerca dessa temática para compreender como se constitui a rede protetiva se faz necessária. Os resultados reforçam a relevância que o Estado tenha presença mais forte e participativa no âmbito assistencial para que as ações integradas da rede funcionem como o Estatuto da Criança e do Adolescente prevê. Tem-se, portanto, que é preciso mais atenção do poder público e maiores investimentos para contribuir no ideal funcionamento do Conselho Tutelar.

A rede socioassistencial é outro elemento que merece atenção. É necessário o fortalecimento dessa rede, uma vez que ela se configura como um ponto fundamental para que o trabalho do Conselho Tutelar seja realizado em consonância com o CREAS/CRAS, Ministério Público e instituições de saúde como é preconizado na lei. É importante que se tenham investimentos nessa área para que possam atuar de forma uniforme no combate à violação dos direitos de crianças e de adolescentes.

Apesar dos desafios no fazer profissional dos conselheiros tutelares, é indispensável a atuação do Conselho Tutelar na realidade brasileira, uma vez que o órgão é responsável por zelar pelos direitos e garantias das crianças e dos adolescentes de acordo com o exposto na 
MOTA, Debora Rute de Paiva; SOUZA, Maciana de Freitas e; HOLANDA, Ana Luiza Pereira. Impasses e reflexões sobre o papel do conselho tutelar. Dignidade Re-Vista, v.6, n.11, dez 2020.

Lei. 8.069/90. Logo, devemos pensar sobre a sua situação e reivindicar junto às instituições responsáveis melhores condições de trabalho para esses profissionais. 


\section{Referências bibliográficas}

AMIN, Andréia Rodrigues. Doutrina de Proteção Integral: aspectos teóricos e práticos. 4 ed. Rio de Janeiro: Lúmen Júris, 2010.

ASSIS, Simone Gonçalves de et al. (orgs.). Teoria e prática dos Conselhos Tutelares e Conselhos de Direitos da Criança e do Adolescente. Rio de Janeiro: Fundação Oswaldo Cruz, Educação a Distância da Escola Nacional de Saúde Pública Sergio Arouca, 2009.

AZEVEDO, Maria Amélia; GUERRA, Viviane Nogueira de Azevedo (orgs.). Infância e Violência doméstica: fronteiras do conhecimento. 5 ed. São Paulo: Cortez, 2009.

BRASIL. Constituição da República Federativa do Brasil. Brasília: Senado Federal, 1988.

.Conselho Nacional dos Direitos da Criança e do Adolescente - Conanda. Resolução $\mathrm{N}^{\mathrm{o}}$ 113, de 19 de abril de 2006. Parâmetros para a institucionalização e fortalecimento do Sistema de Garantia dos Direitos da Criança e do Adolescente.

. Estatuto da criança e do adolescente. 5.ed. Brasília: Senado Federal, Subsecretaria de Edições Técnicas, 2011.

CAMPOS, E. B. O protagonismo do usuário da assistência social na implementação e controle social do SUAS. Caderno de textos: subsídios para debates - participação e controle social do SUAS / Conselho Nacional de Assistência Social, Ministério do Desenvolvimento Social e Combate à Fome. Brasília, DF: CNAS, MDS, 2009.

FALEIROS, Vicente de Paula. Infância e Processo Político no Brasil: a arte de governar crianças. 2 ed. São Paulo: Cortez, 2009.

TAVARES, Patrícia Silveira. A Política de Atendimento: aspectos teóricos e práticos. 4.ed. Rio de Janeiro: Lúmen Júris, 2010.

SANTOS, L. F. et al. Fatores que interferem no enfrentamento da violência infantil por conselheiros tutelares. Saúde em debate, Rio de Janeiro, v.43 n.120, jan/mar 2019. 